\title{
Arquitectura defensiva de la cultura Pueblo en los cañones de la región Mesa Verde, Colorado, EE.UU.
}

\author{
Radosław Palonka
}

\begin{abstract}
Resumen
La cultura Pueblo se desarrolló el suroeste de Norteamérica sin interrupción durante casi tres mil años, experimentando un serie de cambios y transformaciones culturales y sociales. Dichos cambios se manifiestan principalmente en las formas de asentamiento y arquitectura diferenciadoras de otras culturas indígenas de Norteamérica. Desde el siglo VII d.C. aproximadamente las comunidades de la cultura Pueblo erigen edificios de varios pisos, de materiales como adobe, piedra arenisca y madera. A diferencia de las culturas de cazadores-recolectores la cultura Pueblo se caracteriza por su asentamiento permanente y su avanzada agricultura.

El siglo XIII d.C. trae una transformación de las formas de asentamiento de los Pueblo en la región Mesa Verde. Los asentamientos empiezan a trasladarse de zonas planas y abiertas a los bordes y las laderas de los cañones, o incluso a nichos y refugios rocosos de difícil acceso en las empinadas laderas de los cañones. En las rocas crecen asentamientos y ciudades, a menudo rodeados de muros de piedra y difíciles de acceder; al mismo tiempo empiezan a construirse torres de piedra y túneles subterráneos. Todo ello surgía probablemente de consideraciones defensivas, relacionadas con el deterioro de las condiciones ambientales y climáticas, así como con el aumento de conflictos y peleas, tanto dentro de la cultura misma, como probablemente con atacantes de otras tribus.

Uno de los complejos de asentamientos Pueblo del siglo XIII, ubicado en Sand Canyon, Rock Creek Canyon y Graveyard Canyon en la región de Mesa Verde, en Colorado, lleva investigándose desde el año 2011, en el marco del Proyecto Arqueológico Sand Canyon-Castle Rock. Este proyecto arqueológico polaco centra su investigación en la reconstrucción del sistema de asentamientos y en el análisis de la arquitectura defensiva de varias docenas de asentamientos pequeños y un gran asentamiento central (Castle Rock Pueblo). Recientemente las actividades del proyecto abarcan también la documentación y el análisis de los murales y los ejemplos del arte rupestre conservados en los sitios examinados.
\end{abstract}

Palabras clave: Mesa Verde, cultura Pueblo, Colorado, Arquitectura defensiva, Castle Rock Pueblo, torres

Radosław Palonka - Instituto de Arqueología, Universidad Jaguellonica, calle Gołębia 11, 31-007 Cracovia, Polonia, e-mail: radek.palonka@uj.edu.pl, ORCID: 0000-0003-2520-810X

* El artículo es una traducción y extensión del texto „Architektura obronna kultury Pueblo w kanionach regionu Mesa Verde, Kolorado, USA", que apareció en el volumen Indianie Lenni Lenape i inni...Referaty Seminariów Antropologicznych 2009-2014, Referaty Konferencji Naukowej „Być Indianinem to...”, editado por Andrzej J. R. Wala y E. Dżurak. Polish-American Ethnological Society in Memory of Bronislaw Malinowski (PAES/PATE), Atlantic City, pp. 139-163. 


\begin{abstract}
For more than a hundred and twenty years, since the cliff dwellings were discovered in the canyons of Colorado, Utah, and Arizona there has been a debate on the topic of their function and the reasons they were left by the Ancestral Pueblo people. These settlements flourished mostly in the 12th and 13th centuries A.D. and encompass sites located within canyons alcoves and shelters; the second "settlement model" included settlements on the edges/slopes of canyons, associated with stone towers and enclosing walls. In this paper, I focus on the research on Castle Rock Pueblo community, located in the central Mesa Verde region of southwestern Colorado. A result of this research that is conducted since 2011 by the Sand-Canyon Castle Rock Community Archaeological Project has been the precise reconstruction of the defensive settlement system. This research has also shown how such an organism of closely cooperating sites was able to effectively function in a worsening natural and social environment. Ethnohistorical sources from the Euro-American period and analogies to settlement systems in other parts of the world were also taken into consideration.

Keywords: Ancestral Pueblo, Mesa Verde, Castle Rock Pueblo, defensive architecture, towers
\end{abstract}

\title{
Región de Mesa Verde y cultura Pueblo
}

Desarrollándose durante miles de años la cultura Pueblo logró formar comunidades de compleja organización y ocupar gran parte de la Meseta del Colorado, ubicada en el Norte del Suroeste de Norteamérica. A medida de que pasaban las épocas diverosos grupos de la cultura Pueblo asumían la posición dominante en la cultura y la política de alguna parte de la región, siempre influyendo también en otras zonas y determinando de esta manera el ritmo de los cambios y las transformaciones de toda la cultura y la región (Cordell 1997, Plog 1997). Los lugares donde la cultura Pueblo se ha desarrollado más plenamente incluyen: el Cañón del Chaco - hoy en día noroeste de Nuevo México — donde entre los siglos IX y XII la población Pueblo florecía construyendo monumentales obras arquitectónicas de piedra e influyendo de forma importante en el desarrollo de otros grupos Pueblo, manteniendo al mismo tiempo bastante extensos contactos comerciales con las culturas mesoamericanas; el Valle del Río Grande, también en Nuevo México, donde hoy habita la mayoría de la población Pueblo, concentrada en las reservas indias. Otras regiones importantes son: la región de Kayenta en el norte de Arizona y el sur Utah y la región de Mesa Verde, ubicada en la zona donde colindan cuatro estados: Arizona, Colorado, Utah y Nuevo México. Dicha región y la ubicación de los antiguos asentamientos de los Pueblo se conocen también bajo el nombre de las Cuatro Esquinas (Four Corners), debido al hecho de que las fronteras de los cuatro estados se intersectan en un punto formando ángulos rectos, lo que convierte la zona en una atracción turística.

La región Mesa Verde se divide además en varias zonas, y la mayoría de los poblados en acantilados (los llamados centros de asentamiento), es decir, las famosas ciudades de roca de los indios Pueblo, a veces llamados castillos defensivos, como Cliff Palace, Spruce Tree House o Long House, construidos en nichos naturales y refugiados en los acantilados de los cañones se encuentran en su parte central, en la llamada región central de Mesa Verde que, hablando en términos generales, se encuentra en la zona fronteriza entre el sureste de Utah y el suroeste de 

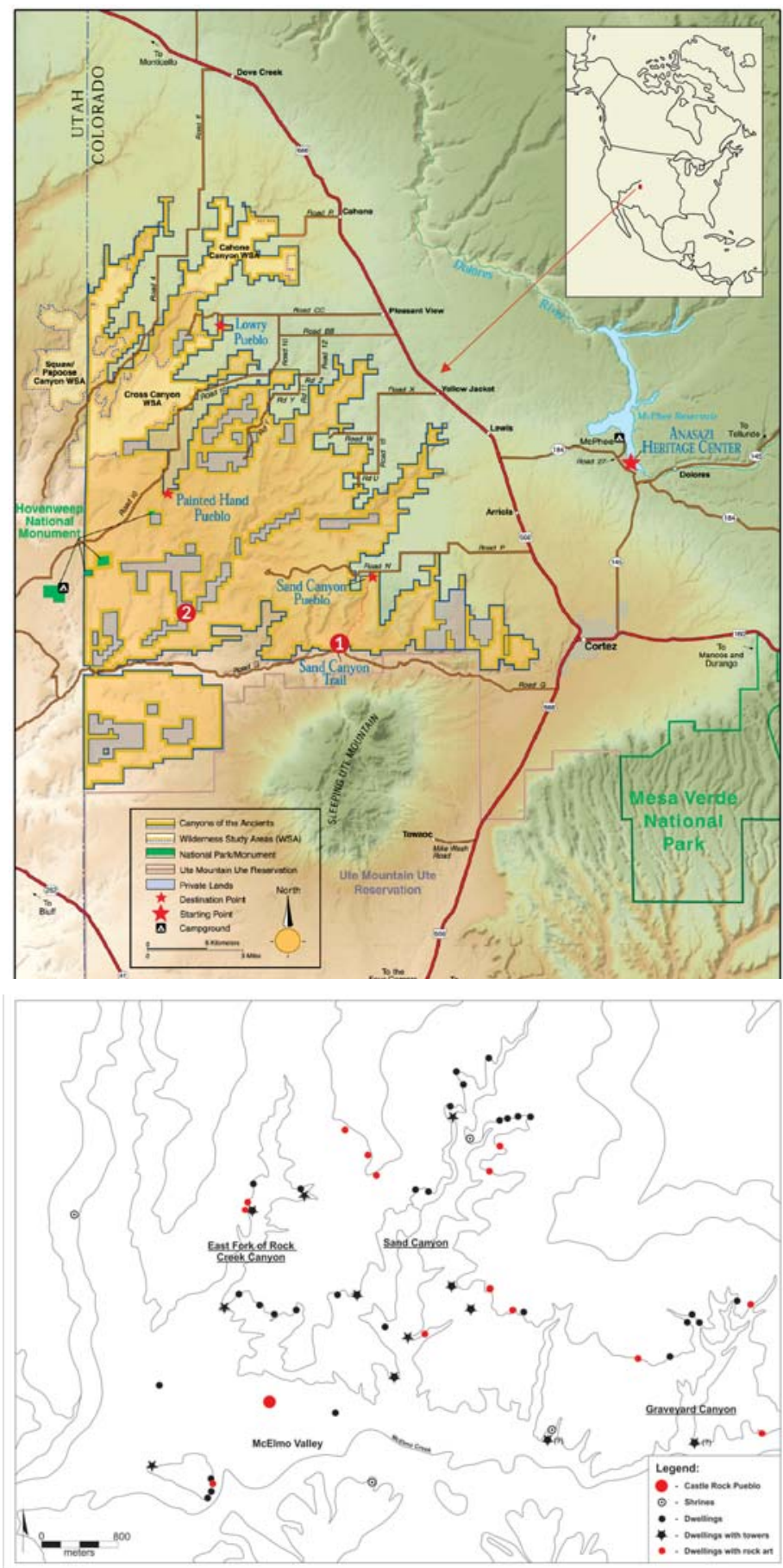

Fig. 1 (a-b). Cañones y conjunto de asentamientos de la antigua cultura Pueblo datos del siglo XIII d.C., estudiados en el marco del proyecto polaco. Los sitios marcados con signos de interrogación indican la cronología incierta de los asentamientos (siglos XII o XIII). Dibujo CANM, M. Znamirowski y R. Palonka. 
Colorado (Varien 2000: 6). Aquí se ubican los famosos parques con poblados de los antiguos indios Pueblo: el Parque Nacional Mesa Verde, el Monumento Nacional Hovenweep y el Monumento Nacional Cañones de los Antiguos - el más joven de las áreas legalmente protegidas de esta región, creado en 2000, donde en 2011 se instaló el proyecto arqueológico polaco Sand Canyon-Castle Rock (Palonka 2013, 2014, 2019; Palonka et al. 2015) (fig. 1a, fig. 1b).

Se estima que la cultura Pueblo empezó a desarrollarse en la región Mesa Verde alrededor del 500 a.C., no obstante las dataciones más recientes indican tiempos más remotos, a medida de descubrir sitios nuevos (Charles 2006; Lipe y Varien 1999). La primera fase relacionada con la cultura Pueblo en la región de Mesa Verde (hasta el año 700 d.C. aprox.) es el llamado período de los Cesteros (Basketmaker period), aún sin vestigios de arquitectura de piedra, ni cerámica. Además de los dos aparecen indicios del cambio económico: intensificación de agricultura (incluido el cultivo de algodón y la cría de pavos) y del comercio, marcando el comienzo del período de los Pueblos. El período de los Pueblos se divide en la región de Mesa Verde en varias fases (Lipe, Varien y Wilshusen 1999): Pueblo I (700-950 d.C.), Pueblo II (950-1150 d.C.) y Pueblo III (1150-1280 d.C.).

A pesar de numerosos cambios y transformaciones espontáneos, así como interacciones culturales con otros amerindios de la región suroeste (las fuentes españolas posteriormente escritas principalmente relatan conflictos con las naciones ute, navajo y apache), y desde el siglo XVI también con los españoles, la población Pueblo logró sobrevivir fundamentalmente en el mismo territorio y preservar gran parte de sus antiguas tradiciones y del legado de sus antepasados. Las comunidades de la antigua cultura Pueblo abandonaron la región Mesa Verde a finales del siglo XIII d.C., es decir mucho antes de que llegaran allí los europeos, sin embargo en otras áreas del suroeste su cultura se ha preservado extraordinariamente hasta el día de hoy. Parece que la mayoría de los Pueblo de la región Mesa Verde migraron hacia el sur y el sureste (Cameron 2006; Lipe 1995; Kohler et al. 2010), hacia los territorios actuales de Arizona y Nuevo México, donde dos siglos y medio después sus descendientes por primera vez conocieron a los conquistadores españoles.

Sin embargo antes, durante casi 1800 años, la población Pueblo encontró en la región de Mesa Verde, a pesar de su clima suroccidental, árido y cálido, condiciones relativamente buenas para la sedentarización permanente basada en el cultivo de maíz, calabaza y frijoles, y desde el siglo VII d.C. aproximadamente, también para la cría de pavos (Lipe y Varien 1999; Matson 1991). Las comunidades Pueblo supieron aprovechar bastante bien los nichos ecológicos de la zona. La región está bastante elevada, desde aproximadamente 1600 m.s.n.m. hasta aproximadamente 2500 m.s.n.m., llegando hasta 3400 m.s.n.m. (con poblados Pueblo permanentes concentrados a la altura máximo de unos 2500 m.s.n.m.). El paisaje predominante son las mesetas, las llamadas mesas, a menudo cortadas por profundos cañones, mientras que las altas cordilleras proporcionaban acceso a la madera como material 
de construcción y diversas especies de animales de caza, como ciervos y osos. Gracias a la ubicación en zonas elevadas podía contarse con más precipitaciones que en otras regiones del suroeste y los suelos eran suficientemente buenos para el cultivo. Todos estos factores posibilitaron un desarrollo bastante estable de la comunidad Pueblo, convirtiendo, para mucho tiempo, Mesa Verde en una de las regiones más importantes del suroeste.

Entre los períodos de relativa tranquilidad y favorables condiciones ambientales y climáticas ocurrían de vez en cuando fluctuaciones climáticas, manifestadas en prolongadas sequías que daban lugar a una disminución del nivel de agua subterránea, dificultando en gran medida la subsistencia de comunidades dependientes de agricultura. En varias ocasiones las sequías llegaron a reducir el número de habitantes de la región Mesa Verde, pero la cultura Pueblo logró sobrevivir todas las perturbaciones. La situación cambió en la segunda mitad del siglo XIII cuando los cambios ambientales y climáticos se volvieron más intensivos, ocasionando, entre otros eventos, la llamada Gran Sequía (Great Drought) de los años 1276-1299, cuyas huellas se conservan perfectamente en los anillos de los árboles usados para construir las casas de los antiguos indios Pueblo. Esos cambios adversos consistieron principalmente en el enfriamiento del clima, disminución de precipitaciones y de los niveles de agua subterránea (Kohler 2000: 195-202; Lipe 1995; Van West y Dean 2000: 19-44). A todo ello se sumaron la degradación mediambiental provocada por los Pueblo mismos (Dean y Van West 2002; Kohler et al. 2005, 2008) y numerosas peleas y conflictos. Los factotres citados se cumularon hasta tal punto que toda la población Pueblo emigró de la región Mesa Verde. Hay que señalar sin embargo que las causas arriba citadas no acaban de explicar los motivos de la migración. De hecho, el motivo principal por el cual las comunidades de la antigua cultura Pueblo abandonaron la región que durante tantos siglos había sido su hogar, sigue siendo objeto de estudios y debates.

\section{Asentamienos defensivos de los indios Pueblo del siglo XIII d.C. en la región Mesa Verde}

En el período de los cesteros, hasta el siglo VII aproximadamente, los asentamientos de la cultura Pueblo eran áun dispersos y los poblados consistían de unos pocos hogares, pocas veces superando varias decenas. Sin embargo ya los poblados de aquel período estaban protegidos por empalizadas, como ocurre en el caso de Knobby Knee, Gilliland y Payne en Colorado (Lipe i Varien 1999; Wilshusen 1999). La fortificación de los asentamientos sugiere algunas perturbaciones o intensificación de conflictos, sin embargo la arquitectura fortificada en forma de empalizadas de madera alrededor de los poblados aún no era común, más bien se trataba de casos particulares. La transición de la construcción semienterrada a la construcción sobre la superficie se produjo alrededor del siglo VII/VIII d.C., cuando ya se usaba ladrillo secado al sol (adobe) o piedra arenisca tratada como 
materiales de construcción, y se erigían edificios de varias plantas, tampoco indica cualquier aumento de riesgo. Hay que señalar sin embargo, que en los edificios de varias plantas las puertas por lo general se colocaban en la primera planta, el acceso era por escaleras de mano, que en caso de emergencia podían retirarse con facilidad.

A la vuelta de los siglos XII y XIII d.C. (período Pueblo III) un aumento significativo del número de habitantes de la región Mesa Verde coincidió con la llamada centralización de los asentamientos, durante la cual la mayoría de la población comenzó a trasladarse a grandes poblados. Alrededor de dichos centros se formaban grupos de hasta varias docenas de aldeas más pequeñas (Lipe y Varien 1999; Varien 1999), conviertiéndose en unos asentamientos agrupados, donde, al parecer, todos los poblados cooperaban estrechamente, lo que pudo tener especial importancia durante los períodos de inestabilidad climática, conflictos y peleas. Las aldeas en tales complejos de asentamiento no se fundaban más lejos que a 4-5 km de distancia del centro del asentamiento. En el siglo XIII d.C. en la región Mesa Verde, hoy zona fronteriza entre Utah y Colorado, funcionaban casi sesenta asentamientos de este tipo, y la población Pueblo total ascendía a 30-45 mil personas (Lipe 2002; Varien et al. 2007; Wilshusen 2002).

Simultáneamente se observa que, a diferencia de los períodos anteriores, los asentamientos, tanto grandes como pequeños, se trasladan de áreas planas y abiertas a los bordes y los acantilados de los cañones (asentamientos tipo canyonhead settlements), o a voladizos y abrigos rocosos naturales en las laderas de los cañones (los llamados asentamientos/poblados acantilados, o cliff $d$ wellings) (fig. 2). En algunos asentamientos los aspectos relacionados con la defensa no solo son notables, sino hasta dominantes. Para hablar sobre la arquitectura defensiva en la región Mesa Verde hay que tomar en consideración varios parámetros, principalmente cabe mencionar: la ubicación de los asentamientos, el acceso al agua, muros alrededor de los asentamientos, torres de piedra y túneles subterráneos que conectan algunos de los edificios; otro factor importante era la cooperación entre los poblados que formaban una comunidad de asentamientos, incluida la advertencia mutua sobre el enemigo (las torres desempeñaban un papel extremadamente importante, ya que servían para enviar señales a otros poblados) (Haas y Creamer 1996; Lightfoot y Kuckelman 2001; Lipe 1995; Kuckelman 2002; LeBlanc 1999; Palonka 2011, 2019). Las aldeas se construían muy cerca de las fuentes de agua o literalmente en el punto donde el arroyo brotaba de la roca arenisca, para rodear el valioso lugar. La escasez del agua era particularmente dolorosa durante aquel período, cuando el clima se volvió más frío y árido, especialmente en la segunda mitad del siglo XIII.

En el caso de la cultura Pueblo es relativamente fácil reconstruir los asentamientos defensivos, ya que en comparación con los vestigios de otras culturas indias de Norteamérica los asentamientos de la población Pueblo se conservaron 


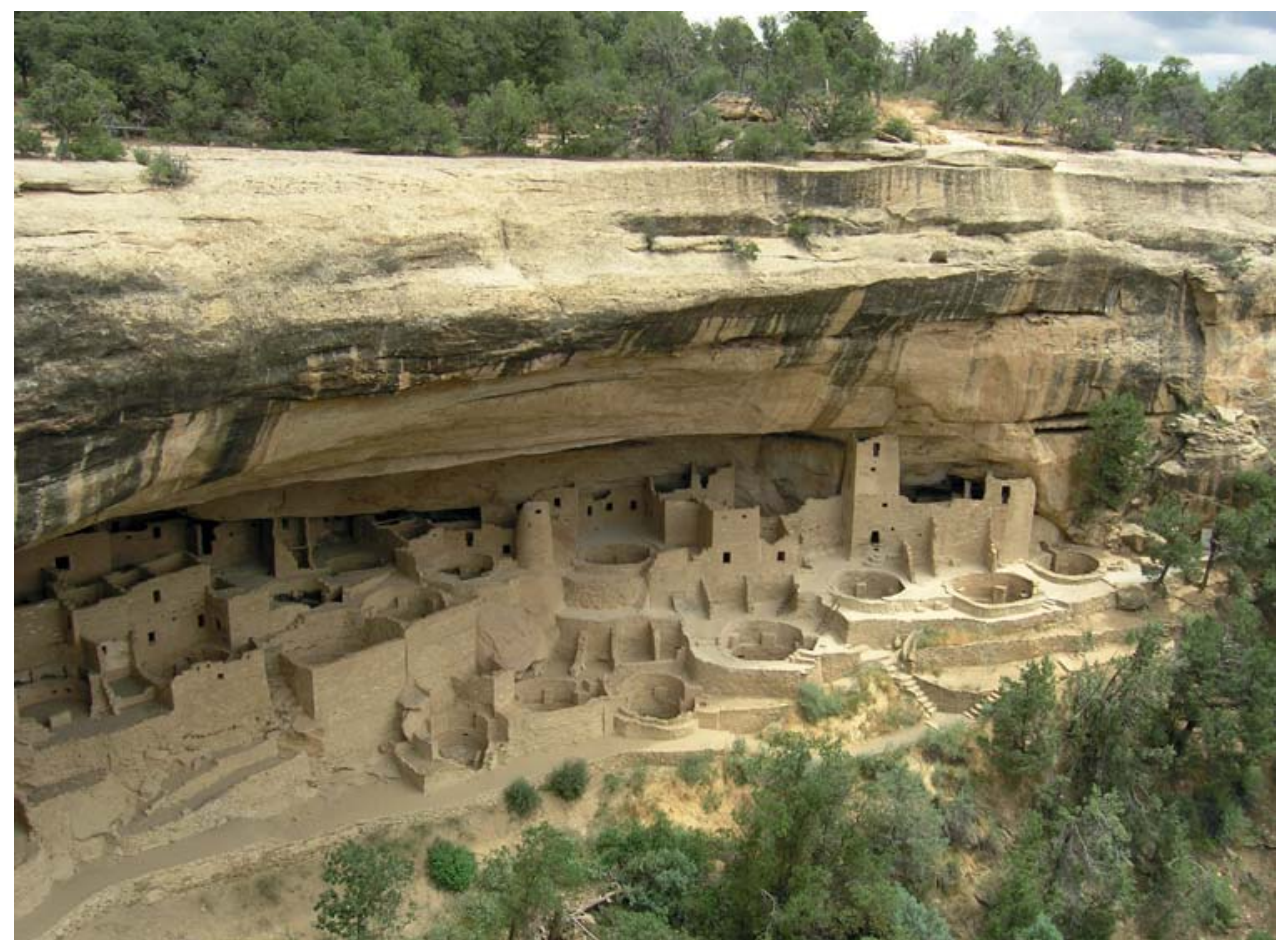

Fig. 2. Sitio Cliff Palace como un ejemplo de sitios defensivos tipo cliff dwellings de la cultura Pueblo en el siglo XIII d.C. de la región Mesa Verde, en la parte sur-occidental de Colorado. Fot. R. Palonka.

hasta el presente en bastante buen estado, precisamente gracias al material usado para la construcción, la ubicación en refugios rocosos y las condiciones ambientales favorables, sobre todo el clima árido y caluroso de la región. Para tales reconstrucciones se pueden aprovechar también las fuentes escritas por los españoles, que documentan su presencia en esta área y mencionan el carácter defensivo de los asentamientos históricos de los indios Pueblo. Las fuentes describen por ejemplo la ubicación inaccesible de los poblados, que los conquistadores tuvieron que asaltar, pero también proporcionan mucha información sobre los métodos de lucha y defensa usados por las comunidades de la cultura Pueblo; por ejemplo explican su táctica que consistía en luchar contra los atacantes fuera de la aldea, para luego, cuando ya no veían otra salida, retirarse a su interior que constituía la línea final de la defensa (a menudo dirigida por los ancianos, quienes, a pesar de no poder luchar, eran los que más experiencia tenían). Gran parte de esta información está asimismo contenida en la tradición oral de los indios Pueblo históricos y contemporáneos, pero también en los cuentos históricos de sus antiguos enemigos, principalmente los navajos y los ute (Bandelier 1916; Ferguson 2002; Ferguson y Colwell-Chanthaphonh 2006; Haas y Creamer 1997; Thompson 2002). Curiosamente, algunos, como los navajos, adoptaron en los siglos XVII y XVIII gran parte de la cultura y 
las creencias de los Pueblo, así como algunos elementos de su arquitectura defensiva, por ejemplo las altas torres de piedra, que los navajos llamaban "pueblitos" y que ahora ellos mismos aprovecharían para defenderse de las invasiones de sus enemigos: los ute, los comanches y los españoles; pero también para transmitir mensajes (Towner 1999, 2004).

A continuación se presentan las características determinantes de la arquitectura y los asentamientos defensivos de la comunidad Pueblo del siglo XIII d.C. en la región Mesa Verde:

- Ubicación de los poblados: a lo largo de los siglos y para diversas culturas la ubicación era uno de los aspectos básicos de las estrategias defensivas. La mayoría de los poblados y los sitios de la cultura Pueblo del siglo XIII se hallan en nichos rocosos difíciles de acceder, pero al mismo tiempo fáciles de defender para los residentes. Por lo general solo uno, o como máximo dos senderos o caminos conducían al poblado, en el caso de los asentamientos acantilados bajando varios metros desde la parte superior de la mesa, o subiendo desde el fondo del cañón. Con frecuencia algún tramo de la ruta de acceso consistía en una escalera o cuerda, o bien surcos, conservados hasta hoy en día, forjados en la roca como peldaños para apoyar pies y manos. En los edificios de varias plantas la comunicación entre niveles llevaba por escaleras de mano, que se retiraban hacia las plantas más altas en caso de amenaza, de modo que los atacantes no podían entrar. La ubicación de muchos asentamientos de este período se cita como el ejemplo más visible del carácter defensivo de esta arquitectura (Kuckelman 2002; LeBlanc 1999). Muchos de esos poblados contaban con su propia fuente de agua, generalmente un arroyo o chorro, y en otros casos con un estanque artificial.

- Murallas que cierran los asentamientos: las poblados y aldeas de acceso fácil, ubicados en los bordes de los cañones (uno de los tipos de sitios arriba mencionados), o en terrenos completamente planos, a menudo estaban cercados por murallas piedra bastante altas, que podían alcanzar 2-3m de altura (Kenzle 1997; Lipe y Varien 1999; Palonka 2011). Los conquistadores que en el siglo XVI invadieron los terrenos que hoy son Arizona y Nuevo México con la intención de conquistar las aldeas y los poblados, así como las fuentes españolas posteriores también mencionan las murallas que protegían los asentamientos de los Pueblo contra los atacantes. Las llamadas cortinas eran otro tipo de muralla, construidas a lo largo de los nichos rocosos para controlar acceso a ellos. En estas murallas se observan grandes cantidades de agujeros pequeños, de unos $10 \times 15 \mathrm{~cm}$ (las llamadas lagunas), probablemente utilizados para vigilar los caminos de acceso al poblado, el área alrededor del poblado, así como edificios individuales dentro del pobaldo (a lo mejor los agujeros podían también servir de troneras, pero cabe señalar que algunos arqueólogos opinan que no eran más que respiraderos, algo así como pequeñas ventanas). 
- Torres: uno de los elementos clave de la arquitectura defensiva en la región Mesa Verde eran torres de piedra, erigidas en el plano circular, rectangular o cuadrado. No siempre se puede estimar la altura de las torres, pero se supone que eran edificios de varias habitaciones, de una, dos o tres plantas, y aunque los restos preservados hasta hoy en día no suelen alcanzar más de 2-3m de altura, en su día debían ser mucho más altas. Las torres más altas de la región preservadas hasta el presente miden entre 6 y $8 \mathrm{~m}$ de altura, como la del sitio Square Tower House en el Parque Nacional Mesa Verde. Muchas están integradas en la línea de la muralla, pero no son menos frecuentes las torres aisladas, alejadas del centro del sitio, o a cierta distancia del mismo, desde varias docenas hasta incluso más de cien metros del asentamiento. Se sugiere a menudo que no necesariamente tuvieran que servir para la defensa, sino para otros fines (Thompson 2004), como divisar animales de caza o vigilar el área para advertir sobre la llegada de agresores. Además hay quienes opinan que algunas de las torres pudieron ser utilizadas para observaciones astronómicas (lo que refuerza esta hipótesis es que las comunidades Pueblo de ese período contaban con un buen conocimiento de constelaciones, solsticios, equinoccios y otros fenómenos astronómicos reconocibles). Sin embargo, cada vez más datos indican que, particularmente en los momentos de peligro, las torres servían principalmente (Bryan 2009; Palonka 2011, 2019) para comunicarse rápidamente con otros poblados que quedaban a la distancia de la vista, usando el humo durante el día y disparos por la noche, para así advertirse mutuamente de la presencia de enemigos o convocar celebraciones y ceremonias.

- Túneles subterráneos: en comparación con otros elementos considerados típicos de la arquitectura defensiva los túneles que conectan los edificios (sobre todo torres y kivas) son poco frecuentes en los sitios. Suelen estar situados en los bordes de asentamientos grandes, por ejemplo cerca de la entrada al asentamiento, permitiendo, en situación de amenaza, encontrar otra ruta de escape hacia el centro del poblado que por el espacio abierto entre los edificios o por los techos. Se descubren túneles también en yacimientos pequeños ubicados en el espacio abierto, que carecían de otros elementos defensivos (ubicación o murallas que rodearan el yacimiento), de modo que los túneles constituían probablemente un elemento de protección para los habitantes de tales aldeas pequeñas, que a veces consistían de tan sólo unos pocos edificios. Edificios conectados por túneles que forman una especie de red de corredores subterráneos también se conocen en otra región de Norteamérica, en las zonas de Alaska y el Ártico canadiense habitadas por los inuit.

- Otros: en el material arqueológico de las excavaciones llevadas a cabo en los asentamientos del siglo XIII se aprecian también vestigios de combates, principalmente edificios quemados y demolidos, esqueletos humanos sin entierros formales, a menudo con huellas dejadas por hachas o puntas de flechas atrapadas 
en los huesos o yaciendo cerca (Kuckelman 2002; LeBlanc 1999). Está evidente que los sobrevivientes casi nunca regresaban a esos asentamientos. La datación dendrocronológica demuestra con claridad que todos los poblados de la región quedaron desolados en un período de unos pocos años (tal vez 3-4 años), entre la década de los 70 y los 80 del siglo XIII. Los combates quedaron representados también en el arte rupestre de la época en forma de pinturas y grabados. Abundan imágenes de guerreros luchando entre sí, armados con arcos, flechas, escudos y una especie de bastones o espadas de madera (Cole 2009; Schaafsma 1980, 2003).

\section{Sistema de defensa y cooperación de los indios Pueblo en Sand Canyon, Rock Creek Canyon y Graveyard Canyon: resultados de investigación del proyecto arqueológico polaco en Colorado}

Los cañones Sand Canyon, East Fork of Rock Creek Canyon y Graveyard Canyon están situados en el condado Montezuma en la parte suroccidental de Colorado, en el centro de la región Mesa Verde. Se hallan en uno de los parques y monumentos nacionales más jóvenes de los EE.UU., fundado en el año 2000 bajo el nombre de Canyons of the Ancients National Monument (CANM). Se trata de una de las zonas con mayor densidad de yacimientos precolombinos e históricos relacionados con las culturas indias, pero también con los primeros colonos españoles y estadounidenses en estas áreas. Los sitios más antiguos encontrados allí datan del período paleoindio (de la cultura Clovis por ejemplo ) y arcaico, sin embargo fue la cultura de los indios Pueblo de los siglos XII y XIII la que dejó vestigios más evidentes, ya que en aquel período encajaban sus edificaciones en nichos y refugios rocosos en los acantilados de los cañones, y en estos sitios, protegidos en gran medida contra las precipitaciones, la arquitectura de piedra de los Pueblo antiguos se preserva en buen estado hasta nuestros días.

En los tres cañones arriba mencionados se descubrieron yacimientos de diversos períodos, y además aproximadamente cuarenta aldeas pequeñas, agrupadas alrededor de un poblado grande (probablemente el centro del asentamiento), Castle Rock Pueblo, que data del siglo XIII d.C.; juntos formaron un complejo de asentamientos, uno de los sesenta complejos de asentamientos que existían en aquel período en la zona fronteriza entre los actuales Colorado y Utah. La primera investigación de superficie y documentación preliminar del complejo de asentamientos de Castle Rock fue iniciada por investigadores estadounidenses en los 70 y 80 del siglo XX (Adler y Metcalf 1992, Gleichman y Gleichman 1992), pero se trataba en gran medida de una investigación preliminar y rudimentaria. A partir del año 2011 el Instituto de Arqueología de la Universidad Jaguelónica de Cracovia está llevando a cabo en estos cañones el primer proyecto arqueológico polaco en los Estados Unidos. El Proyecto Sand Canyon-Castle Rock es dirigido por dr. Radosław Palonka. 


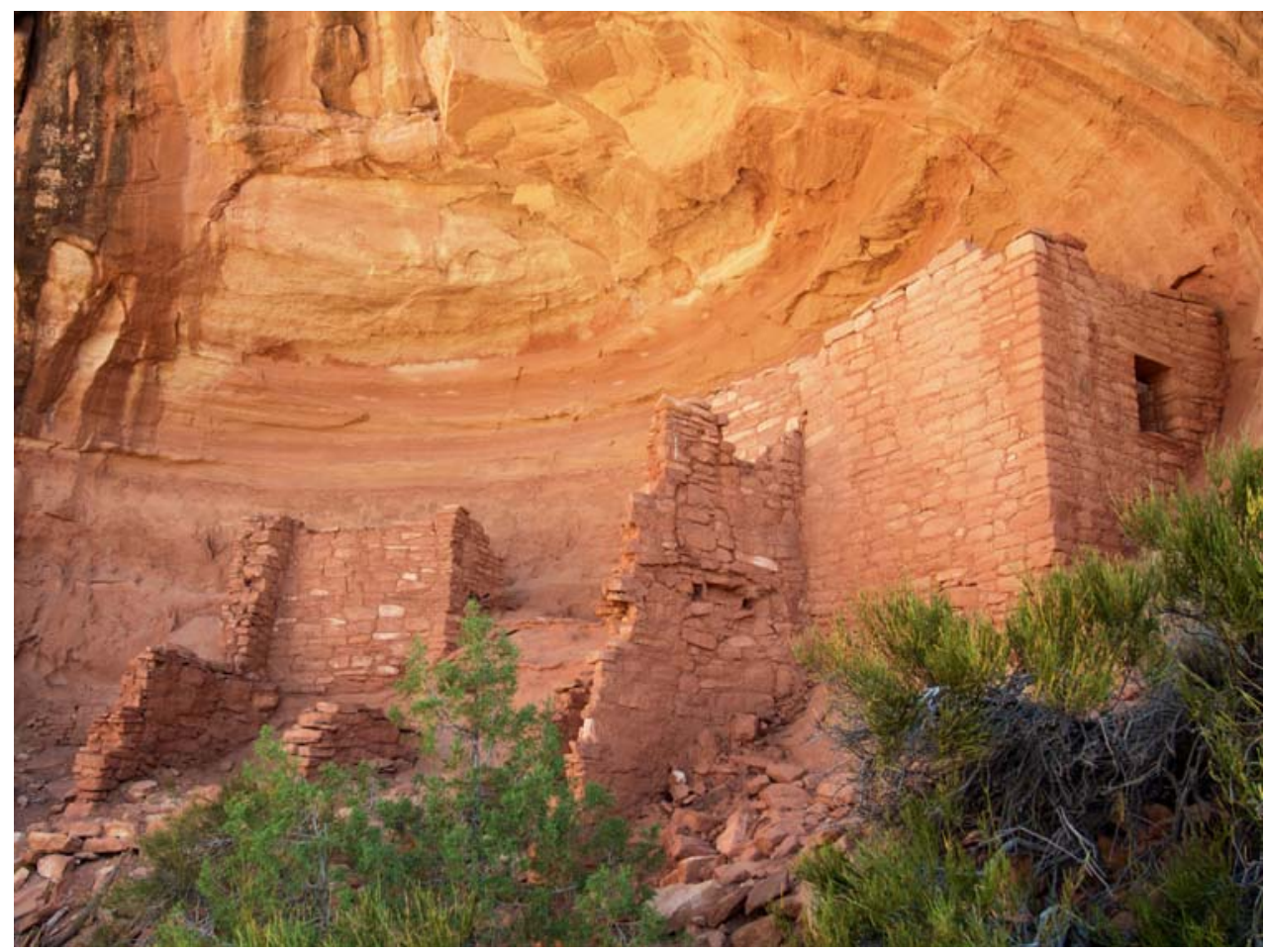

Fig. 3. Sitio Sunny Alcove (5MT135), ubicado en la ladera occidental de Sand Canyon, uno de los ejemplos de asentamientos acantilados de carácter defensivo, construidos en nichos y refugios en las laderas de los cañones, estudiados en el marco del proyecto polaco; rekonstrukcja. Fot. J. Nawrot.

Entre 2011 y 2014 la investigación en el marco del proyecto se centró en analizar y documentar la estructura de asentamientos de la cultura Pueblo en el siglo XIII, incluyendo el análisis de la arquitectura desde el punto de vista de la defensa e intentos de reconstruir las relaciones y los cambios socioculturales. En los años siguientes (2015-2016) se completaron los estudios previos, y además se inició la documentación del arte rupestre. La investigación en el marco del proyecto debe contribuir también a un mejor conocimiento y comprensión de los motivos de la migración de los Pueblo desde los cañones investigados hacia el Sur, que coincidió con el período de una completa desolación de la región Mesa Verde.

La investigación en el marco del proyecto polaco comprendió principalmente pruebas de superficie no invasivas, documentación detallada en forma de descripciones, dibujos y fotografías de la arquitectura de piedra preservada, así como elaboración de planos precisos del sitio con todos los edificios y la topografía del área. Durante tres temporadas (2011-2014) se realizaron también varias pruebas geofísicas no invasivas, que en la mayoría de los sitios arqueológicos permitieron localizar gran número de habitaciones escondidas debajo del suelo. Se puso gran énfasis en las técnicas documentales modernas, como la fotogrametría que permite 


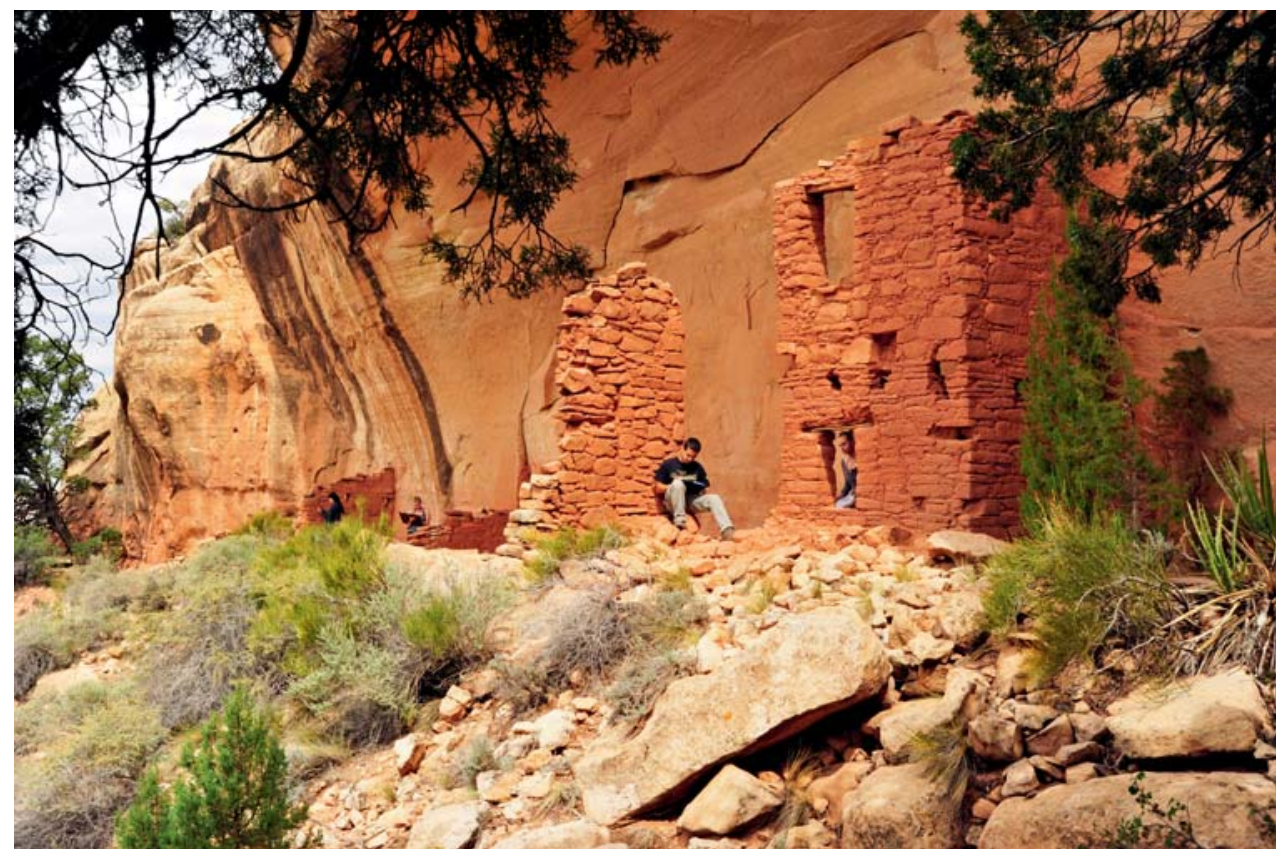

Fig. 4. Documentación gráfica de las paredes del edificio en el sitio Two Story House (5MT1805) en Graveyard Canyon. En el sitio se preservaron también ejemplos de arte rupestre (principalmente petroglifos) y murales en las paredes de los edificios. Fot. R. Słabonski.

generar, mediante una serie de fotos, fotografías de gran superficie en escala de 1: 1 con alta resolución, luego, en las temporadas 2014 y 2016, se utilizó un escáner de láser para documentar y crear modelos $3 \mathrm{D}$ de sitios seleccionados. Al mismo comenzaron los trabajos de prospección arqueológica; en total, hasta finales del año 2016, se examinaron unos treinta sitios arqueológicos. Además, tanto en los sitios ivestigados como en las rocas que se hallaban en la cercanía de los mismos se encontraron y documentaron numerosos ejemplos de arte rupestre (grabados y pinturas), así como murales, es decir mortero de colores o pinturas conservados en las paredes de los edificios, algunos de ellos desconocidos para los investigadores estadounidenses,

Los sitios estudiados por el equipo polaco en los cañones se pueden dividir en tres tipos principales en función de su ubicación y de potencial de defensa. Un sitio, el más grande del conjunto estudiado: Castle Rock Pueblo (sitio 5MT1825), representa el primer tipo. Debido a su tamaño es el sitio más importante del conjunto, con casi 60 edificios que pudieron ser habitados por 75 hasta 150 personas (Kuckelman 2000). Algunos edificios de Castle Rock Pueblo están situados encima de una formación rocosa de 20 metros de altura, pero la mayoría rodea la colina y están cercados por una muralla de piedra. El sitio comprende 9 torres, probablemente tres situadas en la cima de la colina. 
Otro tipo de asentamiento, el más frecuente en el conjunto estudiado, son los asentamientos acantilados, es decir, poblados construidos en nichos o en laderas debajo de estos refugios rocosos, o en los terrenos planos al pie de los acantilados. De los más de cuarenta poblados que forman el complejo, treinta y uno son asentamientos acantilados o situados a gran altura en la ladera del cañón. Los estudios geofísicos realizados en el marco de nuestro proyecto demuestran que las partes de los poblados ubicadas fuera de los nichos eran al menos tan grandes como las partes dentro de los nichos, y en muchos casos había más edificios fuera, que dentro de los espacios limitados de los nichos y las cuevas; lo que a su vez es un buen indicio del número de habitantes de los poblados individuales y de todo el conjunto de asentamientos: está claro que las estimaciones anteriores deberían verificarse y probablemente más personas

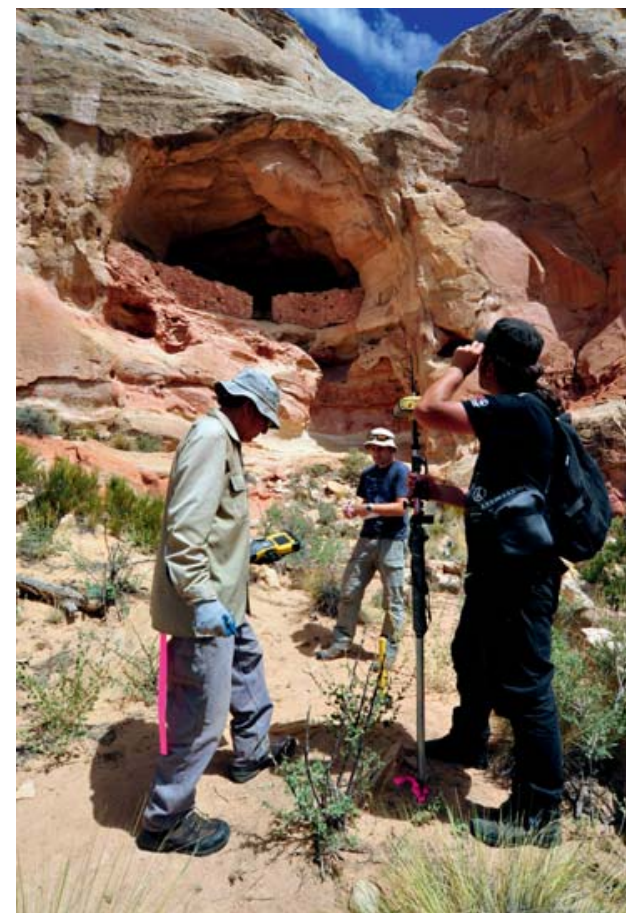

Fig. 5. Trabajos geodésicos y de documentación en zael sitio 5MT1826 en Rock Creek Canyon. El sitio fue probablemente una especie de refugio, donde la población que habitaba cerca se escondía en caso de peligro. Fot. R. Słabonski. vivieron allí de lo que se inicialmente suponía.

El último tipo de asentamiento se aprecia en los nueve sitios ubicados en un área plana y abierta (incluyendo uno encima de una columna rocosa y uno en la cima de una meseta). Son en su mayoría sitios muy pequeños (de dos o tres edificios) o aisladas torres de piedra, así como cuatro círculos de piedra (los llamados shrines, o santuarios), que según algunos investigadores servían para prácticas religiosas o tal vez para delimitar el alcance del complejo de poblados (Ortman 2008: 134-138).

Tanto en Castle Rock Pueblo, como en las aldeas pequeñas, se observan los rasgos distintivos de la arquitectura defensiva, principalmente su ubicación, pero también elementos de la arquitectura defensiva. Los sitios en los acantilados y algunas torres son muy difíciles de acceder, en al menos un par de casos se necesitaban escaleras de 3-4 metros de altura para entrar (en el sitio 5MT1829 se necesitaba una escalera de al menos 10-12 m, así que para las pruebas del proyecto se apilaron tres enebros marchitos uno encima del otro, y por esta estructura subían los guardias del parque y los miembros del equipo). En dos o tres sitios se encontraron huellas de surcos en la roca para apoyar pies y manos, que ayudaban a llegar a los asentamientos; 


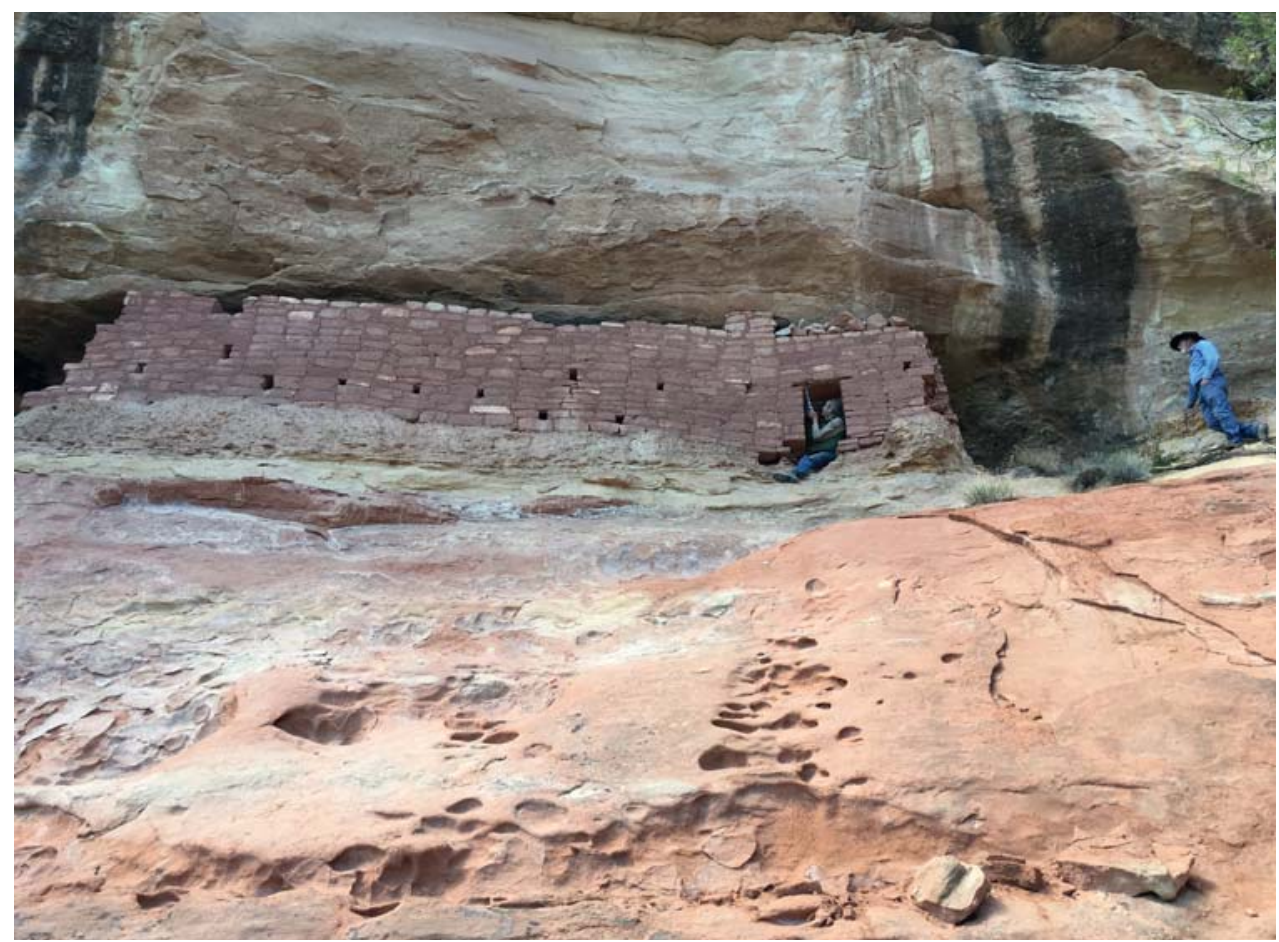

Fig. 6. Sitio de refugio y vivienda 5MT1831 en East Fork of Rock Creek Canyon (fechas dendrocronológicas demuestran la fecha de su construcción 1254/1255 d.C.). Fot. M. Znamirowski.

ciertamente, al menos en algunos tramos, también se usaban cuerdas para facilitar la escalada.

Adicionalmente en algunos sitios aún existen murallas construidas a lo largo del nicho en la roca, con solo una entrada en todo el muro (esto se aplica a al menos tres sitios, a los que se pueden sumar otros, donde las murallas aún se observan en las fotos del siglo XIX), que protegían la entrada al nicho de forma bastante efectiva, limitándola a un solo punto. En otros sitios sólo se preservaron fragmentos de las murallas, pero está claro que tuvieron que existir. En el caso de dos sitios: 5MT1826 (fig. 5) y 5MT1831 (Fortified House - casa fortificada) (fig. 6) no hay ningunos edificios detrás de la muralla, solo un amplio espacio vacío, mientras que en las laderas y el terreno plano debajo de los nichos hay vestigios de edificios. Los espacios podían servir como refugios, es decir un lugar adonde escapar y esconderse en caso de un ataque. En la mayoría de los tramos externos de las murallas se aprecian agujeros de observación, en los tramos más largos incluso 10-11 agujeros, usados probablemente para observar el área fuera del nicho rocoso, tanto los edificios debajo, como todo el alrededor, incluidos los senderos de acceso al mismo.

Las torres eran un elemento importante en todo este sistema de defensa. En los cañones examinados hay ruinas de al menos dieciséis torres de piedra (nueve de 

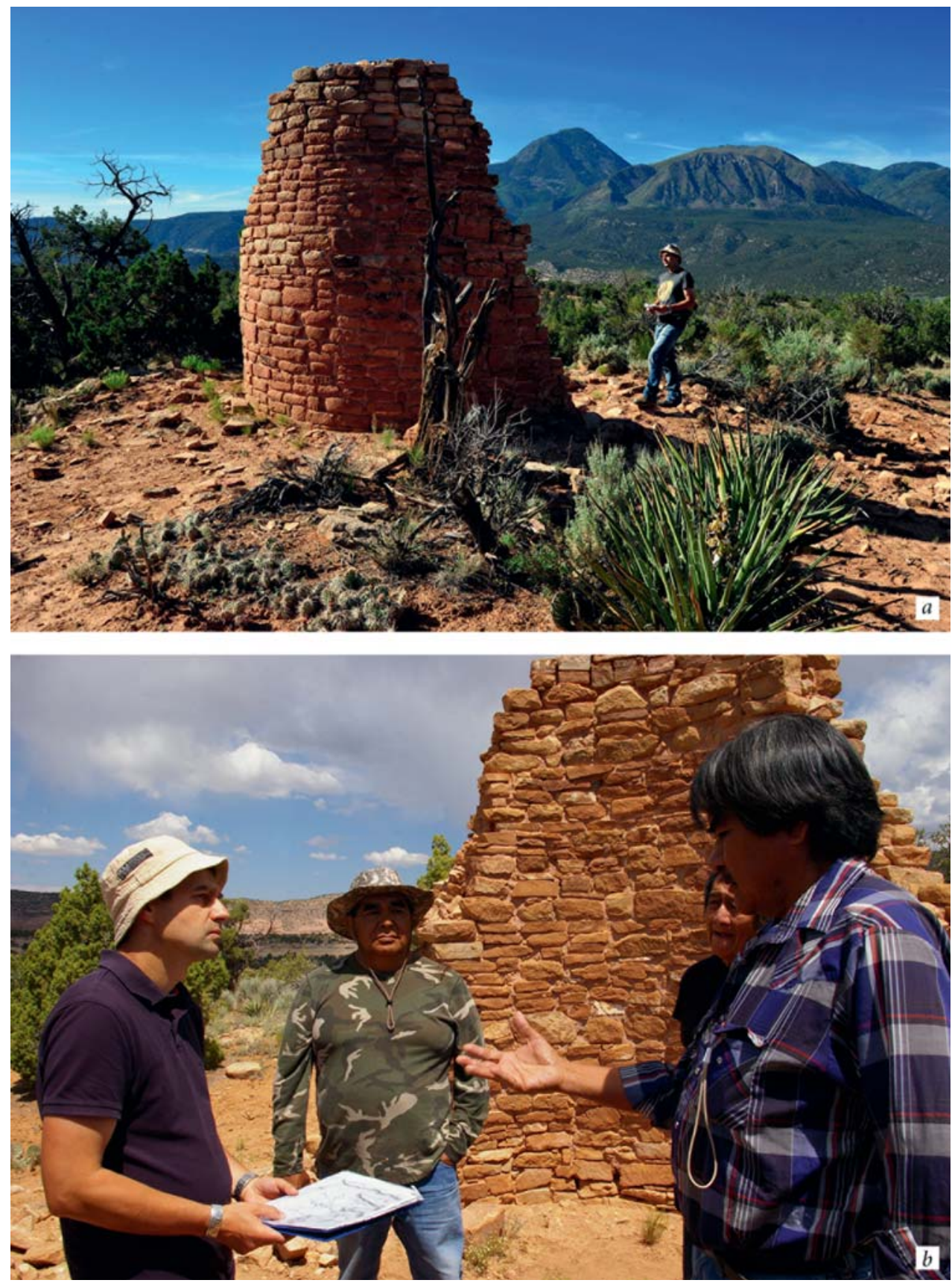

Fig. 7. La Torre Mad Dog Tower (5MT181), en el fondo la montaña más alta de la zona, Sleeping Ute Mountain (hoy reserva de los ute); probablemente era una montaña sagrada para los Pueblo antiguos (a), fot. R. Słabonski y (b) consultas con las personas Indígenas Hopi sobre la arquitectura defensiva y arte rupestre de los antiguos Indígenas Pueblo. Fot. R. Kozłowski. 


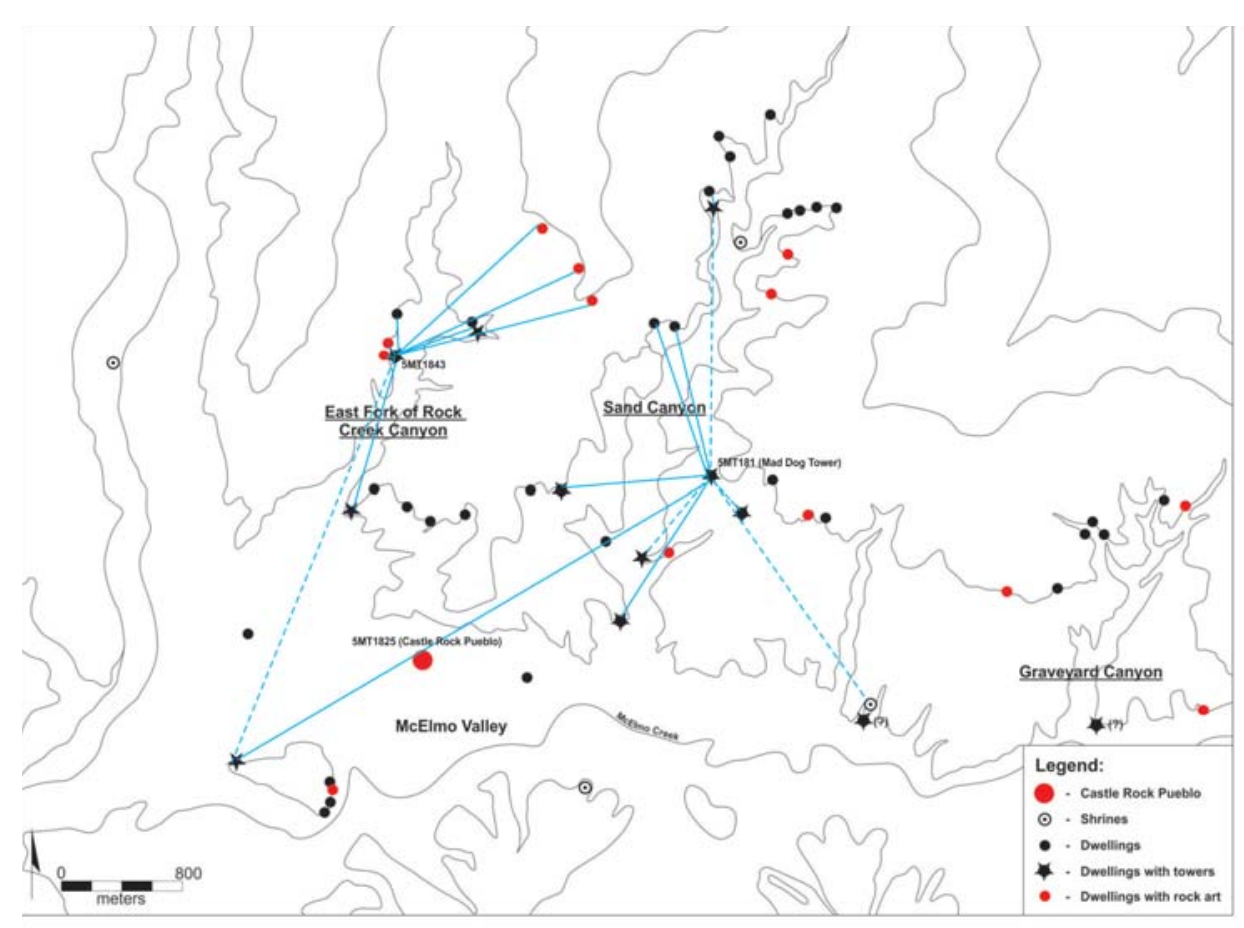

Fig. 8. Dibujo de la vista hacia los asentamientos vistos desde la torre 5MT181 (Mad Dog Tower) en Sand Canyon y desde la torre 5MT1842 en East Fork of Rock Creek Canyon. Dibujo: M. Znamirowski.

ellas en Castle Rock Pueblo). La torre con más altura preservada tiene 3,2 m y está situada en el sitio Mad Dog Tower (5MT181) (fig. 7), en la parte oriental de Sand Canyon (es difícil estimar cuál era su altura total cuando era en uso, en el siglo XIII). Algunas torres en poblados pequeños están ubicadas en su interior (pero siempre de tal manera que pueda mantenerse contacto visual con otros poblados, mientras que no siempre son visibles de otras partes del poblado), algunas están a una distancia de hasta $100-120 \mathrm{~m}$ del poblado, pero siempre permitiendo observar un asentamiento determinado y al menos 3 o 4 otros, incluso bastante alejados. Algunas torres se encuentran en terrenos bastante planos y sus partes bajas son fáciles de acceder, pero otras están situadas en lugares extremadamente difíciles de alcanzar (fig. 8).

Los estudios permitieron dividir los más de cuarenta asentamientos estudiados en seis grupos de sitios, en los cuales entre cuatro y ocho asentamientos de cada grupo tuvieron contacto visual directo o mediante las torres. De día las señales se transmitían usando humo o espejos de pirita pulida, de noche con el fuego. Así que ejemplos de uso de "señales de humo" popularizados por los libros de aventura y los westerns, eran hechos reales en estos terrenos, lo que demuestran varias fuentes escritas de aquel período histórico. En Nuevo México, los asentamientos de los antiguos navajos se realizaron varios experimentos para averiguar la posibilidad de contacto visual entre los llamados pueblitos (p.ej.: Bryan 2009; Schul- 

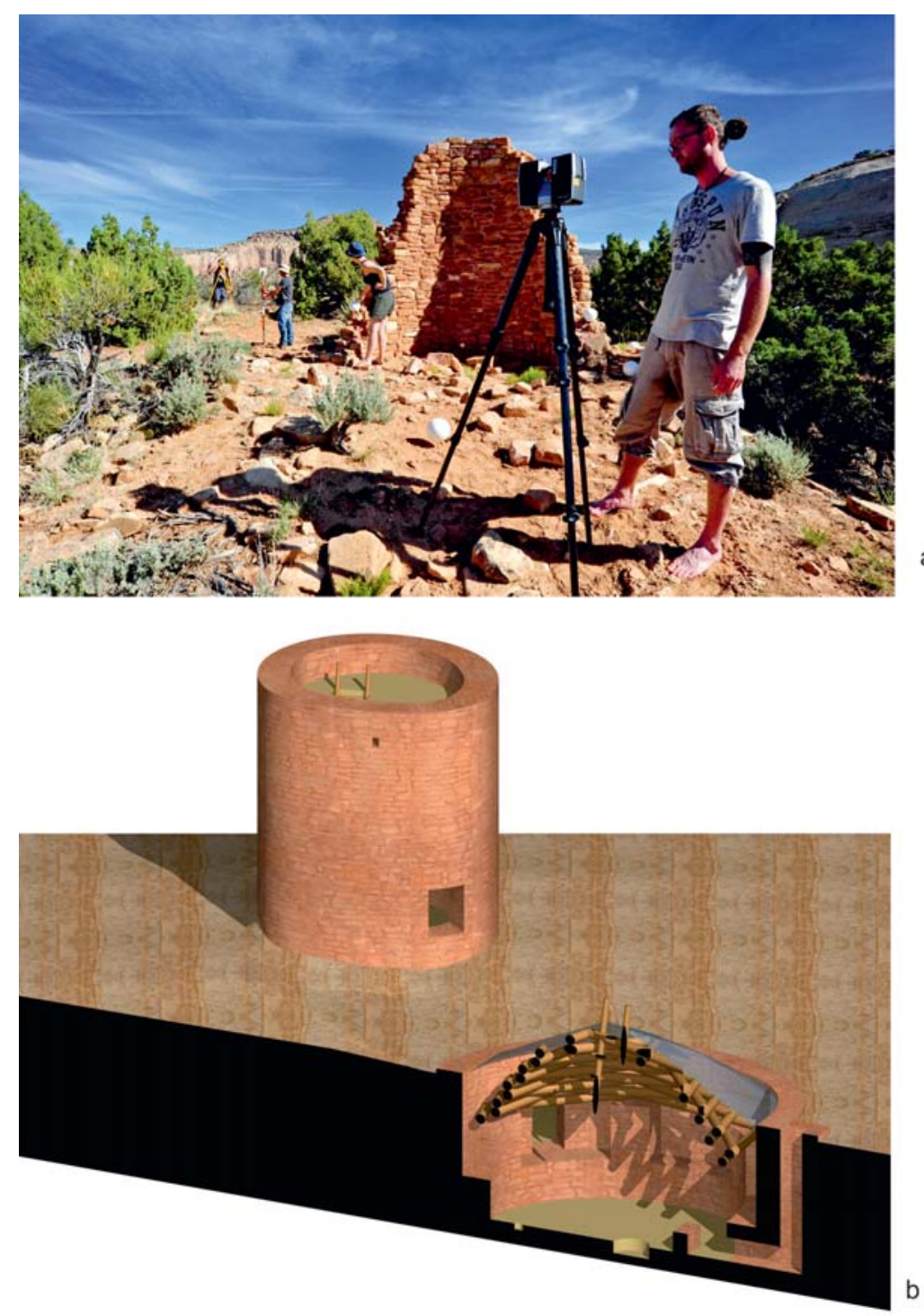

Fig. 9. (a) Investigación en una de las torres, Mad Dog Tower, probablemente usada para transmitir señales; la imagen proviene de las pruebas con escáner de láser para una posterior reconstrucción 3D. Fot. R. Słabonski y (b) reconstrucción de la torre y kiva conectadas con un túnel subterráneo. Dibujo: J. Czechowicz y A. Bojęś-Białasik.

man 1950). Experimentos similares realizados en los sitios de la cultura Pueblo en Nuevo México y el sur de Colorado, (p.ej.: Van Dyke et al., 2016) demostraron que las señales podían transmitirse con bastante rapidez a una distancia de hasta varias docenas de kilómetros. Era, sin duda, la forma de comunicación más rápida de las conocidas en aquel momento. 

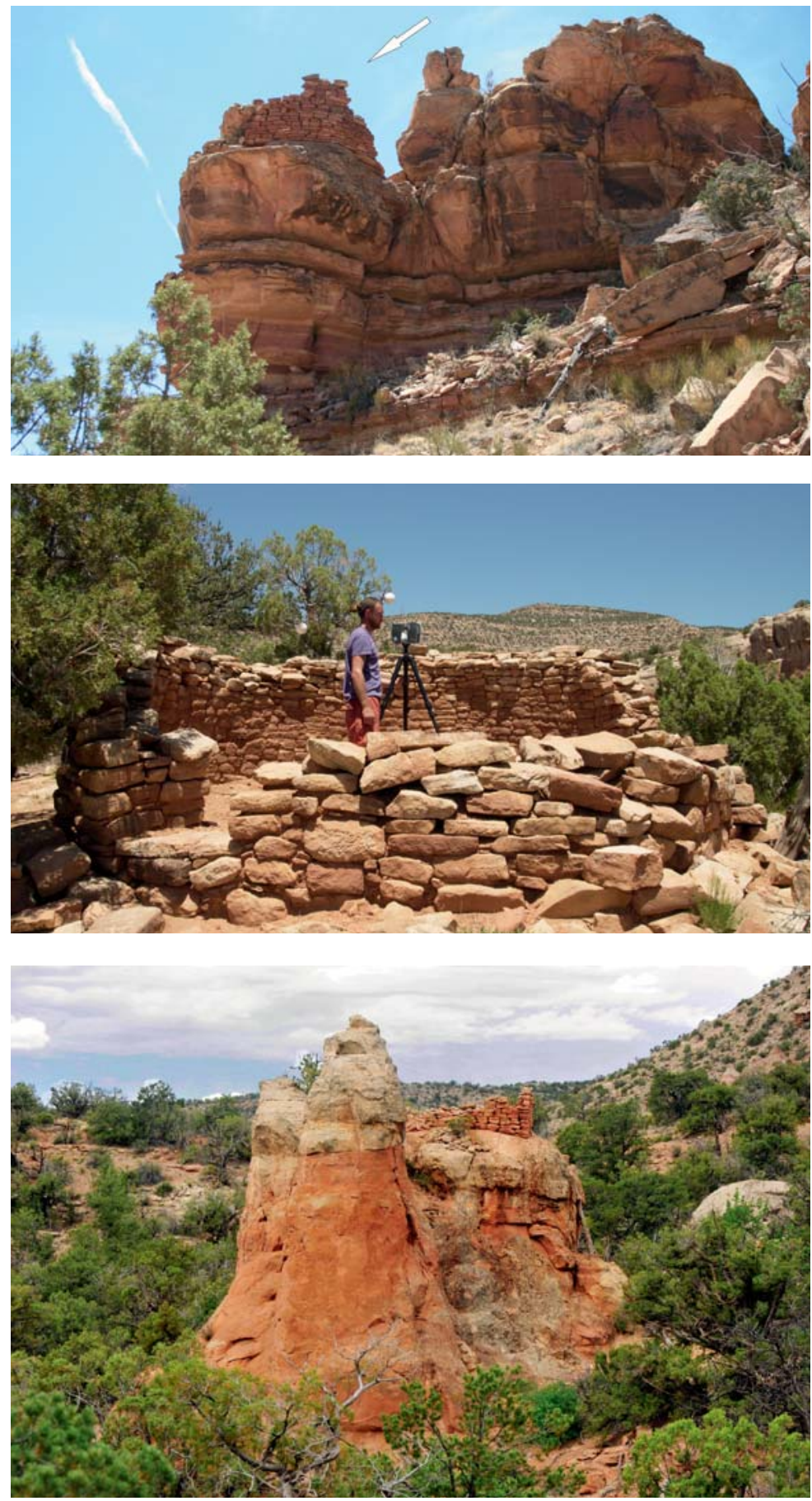

Fig. 10. Tres torres localizadas en Sand Canyon (a-b) (sitios 5MT261 y 5MT13446) y en East Fork of Rock Creek Canyon (c) (5MT1843), cuya función era posiblemente comunicación visual y transmisión de señales entre asentamientos. Dibujo: M. Znamirowski. 
Por lo tanto, parece que las torres y todo el sistema de comunicación y advertencia basado en ellas fueron uno de los elementos más importantes, si no la medida clave, decisiva para la supervivencia de la comunidad, especialmente considerando que probablemente no era una comunidad numerosa y vivía dispersa sobre un área bastante grande, siempre a unos kilómetros de otro grupo y en un terreno muy difícil de atravesar. En las próximas temporadas se planifica realizar un experimento en los sitios de los cañones incluidos en el proyecto. La prohibición de uso de fuego en todo el parque (debido al alto riesgo de incendios en áreas áridas) será una dificultad, por lo que se tiene previsto usar espejos o bengalas especiales.

Hay que mencionar sin embargo, que a pesar de los indudables valores defensivos y la ubicación específica de las torres que posibilita el contacto visual y la transmisión de señales entre los asentamientos en caso de peligro, existen también otras teorías relativas a sus funciones potenciales. Una de ellas es la posibilidad de realizar observaciones astronómicas en las torres (las comunidades Pueblo tenían excelentes conocimientos de los fenómenos astronómicos y de ciertos cuerpos celestes), otra es la observación del área para cazar animales o transmitir señales no solo con fines defensivos, sino también para convocar ceremonias y celebraciones, entre otras (Johnson 2003; Thompson 2004).

Otra característica del asentamiento defensivo, hasta ahora identificada en tan solo uno de los sitios del conjunto - el Mad Dog Tower (5MT181), fueron los túneles subterráneos que conectaban los edificios. En Mad Dog Tower un túnel subterráneo de 3 metros de longitud conecta la torre con un edificio subterráneo (kiva). La torre y las estructuras que la acompañan están situadas sobre un terreno plano, de ahí posiblemente la necesidad de construir un túnel subterráneo para poder escapar de un edificio a otro en caso de peligro. Sin embargo, también se consideran otras posibles funciones de dicho túnel, por ejemplo religiosas (de acuerdo con las creencias históricas y contemporáneas de los indios Pueblo sus antepasados vinieron del mundo subterráneo) (fig. 9). Los túneles subterráneos no son comunes, pero durante el período en cuestión en la región Mesa Verde se construían con bastante frecuencia.

Otra característica de los asentamientos de los Pueblo en los cañones incluidos en el proyecto es la orientación de la mayoría de los sitios hacia el sur o sureste, lo que probablemente permitía acumular más calor y luz solar durante el invierno. La orientación hacia el sur coincide con la ubicación del pico más alto de la zona, Sleeping Ute Mountain, que se eleva a una altura de 2996 metros sobre el nivel del mar, y su distancia desde los sitios es de tan solo 3-5 kilómetros. Para las comunidades ute modernas, que hoy en día tienen su reserva allí, es una montaña sagrada, e igualmente lo es para los indios Pueblo (por ejemplo hopi) que actualmente viven a unos 250-300 kilómetros al sur de sus antiguos territorios. Los Pueblo la llaman a veces "la montaña del oso". Este es solo un ejemplo de la relación entre la arquitectura, la ubicación de los asentamientos, la iconografía del arte 

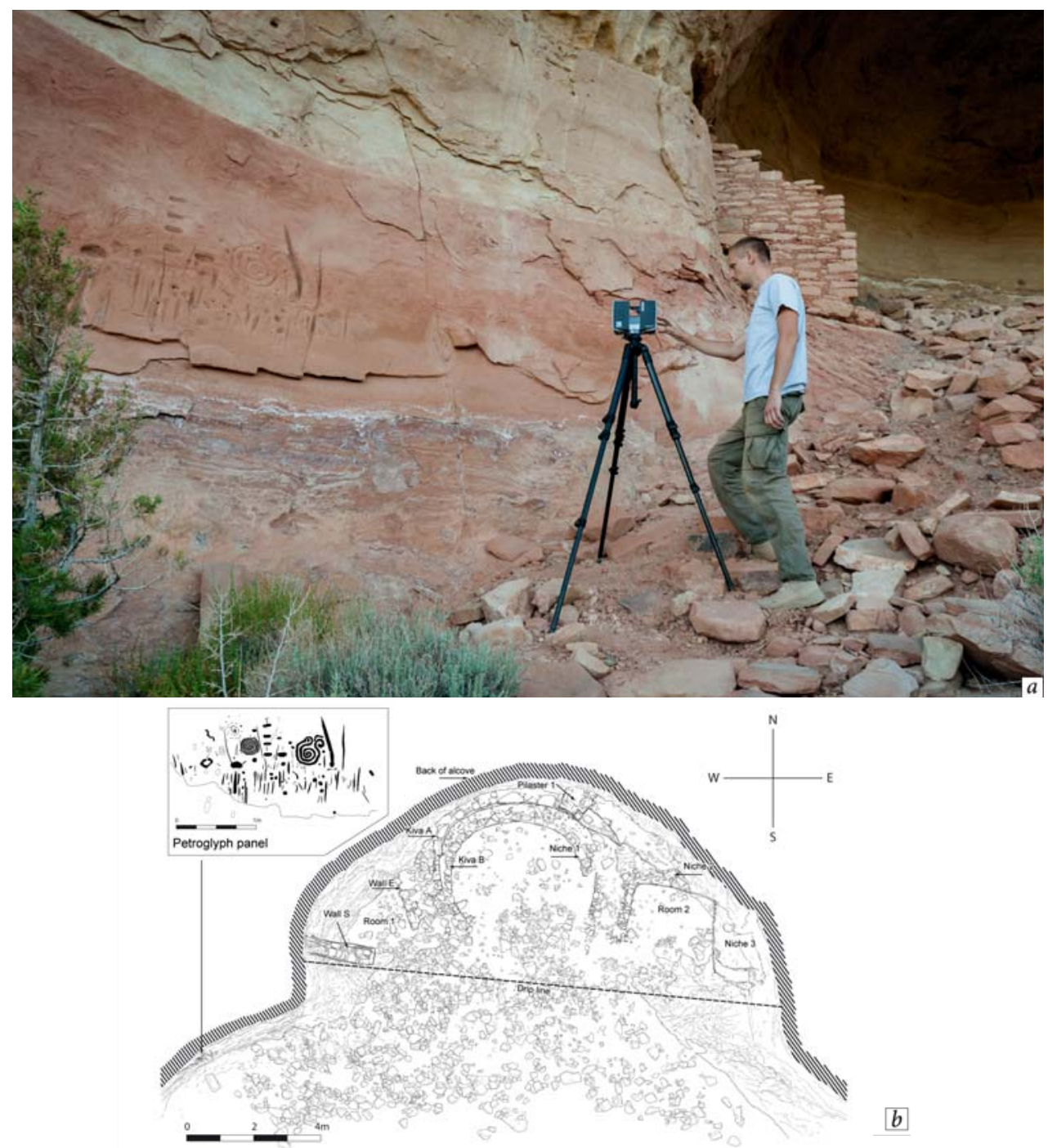

$b$

Fig. 11. Ejemplos de petroglifos en el sitio 5MT129 en Sand Canyon, entre los motivos visibles se distinguen los círculos concéntricos que según los Pueblo modernos significan fuentes de agua, y las espirales que simbolizan caminata o migración. El panel se encuentra fuera del nicho rocoso, al lado del sitio arquitectónico. Fot. M. Znamirowski; dibujo B. Zych y K. Ciomek.

rupestre y de los murales que representan las montañas marcadas esquemáticamente en el paisaje circundante y, probablemente, también con las prácticas religiosas. Cabe subrayar que casi todos los asentamientos contaban con una fuente de agua en su interior o en las proximidades. Hay ejemplos probables de pequeños estanques de agua tallados en roca, y en al menos dos o tres casos una especie de canalones que podían suministrar agua directamente desde la meseta al estanque abajo. 
Aparte de las características materiales que pueden atestiguar la naturaleza defensiva de los asentamientos de los Pueblo en los cañones investigados en el marco del proyecto existe información contenida en la tradición oral de los antiguos Pueblo (principalmente los hopi), relacionado específicamente con el sitio Castle Rock Pueblo - el más grande del conjunto de asentamientos estudiados. Según los testimonios recogidos en la segunda mitad del siglo XIX los ancestros de los hopi construyeron en este asentamiento y otros circundantes sus primeras moradas defensivas, donde tenían que "vivir como golondrinas" en nichos en los acantilados rocosos de los cañones, por miedo a los enemigos que venían cada año para robarles maíz y calabaza. Una vez, sin embargo, los atacantes no se fueron, sino que trajeron a sus familias y se quedaron con ellos al pie de las moradas de los Pueblo. Al final atacaron el asentamiento más grande. Los habitantes se defendieron durante muchos días, por lo que decidieron enviar a las mujeres y los niños lejos del asentamiento, hacia el sur, por una ruta secreta. Los guerreros que se quedaron en el poblado finalmente derrotaron a los invasores, pero perecieron tantos defensores que los que sobrevivieron decidieron seguir a sus esposas e hijos y abandonar Castle Rock Pueblo y otras aldeas del área para siempre (Kuckelman 2000). Así en resumen se relatan los hechos según la tradición oral transmitida de generación en generación, y en gran parte confirmada por descubrimientos arqueológicos, que cien años después del registro de este cuento encontraron huellas de quema y demolición de gran parte del asentamiento. La relación de los hopi identifica a los atacantes específicamente como indios ute. Curiosamente, hoy la frontera de la reserva de ute se encuentra a 2 kilómetros de Castle Rock Pueblo, y los propios ute son reacios a referirse a las antiguas ruinas de los asentamientos Pueblo, muchos de los cuales todavía están en su reserva.

\section{Conclusiones}

En el siglo XIII d.C. en la región Mesa Verde, en la zona fronteriza entre Utah y Colorado, había más de sesenta conjuntos de asentamientos, cada uno formado por un poblado grande y entre una y varias decenas de pequeñas aldeas; la población total probablemente rondaba 30-45 mil personas. Uno de los conjuntos estudiados en el marco del proyecto arqueológico polaco es la llamada Comunidad Castle Rock, consistente en más de cuarenta aldeas dispersas por tres cañones: Sand Canyon, Rock Creek Canyon y Graveyard Canyon, alrededor de un poblado grande: Castle Rock Pueblo.

La mayoría de sitios anteriores al siglo XIII se construyeron en áreas abiertas y planas, pero a partir de principios de este siglo los Pueblo se instalaban en refugios y nichos rocosos en las laderas de los cañones - estos son los llamados asentamientos acantilados, como las famosas ciudades rocosas en el Parque Nacional Mesa Verde en Colorado: Cliff Palace, Balcony House y Spruce Tree House. Otro tipo de asentamientos - los llamados canyon-head settlements - fueron cons- 
truidos a borde de los cañones y en sus laderas y adicionalmente protegidos de áreas planas por altas murallas de piedra. Tanto la ubicación de los asentamientos como ciertas edificaciones y elementos arquitectónicos (torres de piedra, murallas que cercan asentamientos enteros o que defienden la entrada a refugios rocosos, túneles subterráneos que conectan algunos edificios del asentamiento) indican su naturaleza defensiva y la intensificación de conflictos y peleas. Estas características son presentes en el poblado más grande del conjunto estudiado, y en todos los asentamientos alrededor de Castle Rock Pueblo.

Se indica que los posibles enemigos de la población Pueblo en la región de Mesa Verde eran los grupos de atapascos (apaches y navajos), cuyas primeras huellas en el suroeste efectivamente datan del siglo XIII, pero no eran desde luego grupos suficientemente grandes para amenazar las numerosas y bien organizadas comunidades de los Pueblo. Otro Pueblo tomado en consideración son los usuarios de las lenguas númicas (principalmente los antepasados de los ute modernos), que probablemente llegaron del oeste, de los hoy territorios de Nevada y Utah. Sin embargo recientemente cada vez más evidencias indican que los conflictos y peleas surgían dentro de la misma cultura Pueblo, entre los asentamientos o complejos de asentamientos, debido, sobre todo, a la creciente escasez de terrenos cultivable y fuentes de agua.

Lo que confirma indirectamente los conflictos con otros grupos (incluidos los ute) es la tradición oral de los hopi registrada en la segunda mitad del siglo $\mathrm{XIX}$, antes de que existieran profesionales estudios etnográficos y arqueológicos, y que hace referencia al sitio más grande del complejo de asentamientos Castle Rock Pueblo. La prospección arqueológica realizada allí en la década de los 90 por el Centro Arqueológico Crow Canyon reveló que todo el asentamiento fue destruido y mucha parte de los habitantes fueron asesinados y dejados sin entierro. No todos los asentamientos en Mesa Verde corrieron el mismo destino, pero Sand Canyon Pueblo y Goodman Point Pueblo - mucho más grandes asentamientos centrales de otros complejos cercanos, ubicados a varios kilómetros de Castle Rock Pueblo, también fueron atacados y, al menos parcialmente, destruidos.

La mayoría de los sitios del grupo de asentamientos alrededor de Castle Rock Pueblo están ubicados en lugares de difícil acceso, lo que al mismo tiempo facilita la defensa, siempre que se acumule suficiente agua y alimentos. Los alimentos probablemente eran almacenados en algunos edificios situados a gran altura, probablemente para poder protegerlos de los mismos miembros de la comunidad y distribuirlos en períodos de hambre y sequía. Algunos de los sitios eran refugios, como los conocidos también en la arquitectura defensiva europea, por ejemplo la medieval. No eran lugares destinados para habitación permanente, sino para esconderse en caso de peligro. En el conjunto de asentamientos de Castle Rock se encontraron al menos tres sitios de este tipo. En muchos de los asentamientos acantilados del complejo de estudiado, no necesariamente los que cumplían la función de refugio, se descubrieron murallas que protegían las entradas a una cueva o un refugio 
rocoso. Habitualmente tal muralla amparaba toda la apertura de la cueva, con una sola entrada al interior, generalmente a mitad de la longitud de la muralla.

Los elementos clave de la arquitectura defensiva, que además permitían el contacto visual y la posibilidad de transmitir información a largas distancias, eran torres de piedra, redondas o rectangulares. Se erigían tanto en los propios asentamientos, como a cierta distancia de ellos, desde varias docenas hasta más de cien metros del poblado, en un punto que permitiera ver claramente la torre del asentamiento más cercano y las de al menos otras tres o cuatro otros yacimientos. Por lo tanto, parece lógico explicar que, además de valores indudablemente defensivos, su función principal era transmitir señales (con fuego por la noche y de día con humo o espejos, por ejemplo de pirita pulida). Lo que, por supuesto, no excluye otras funciones adicionales de estos edificios, como convocación de ceremonias y observaciones del cielo, por ejemplo para designar el calendario, incluidas ciertas ceremonias relacionadas con la agricultura.

Los asentamientos y las torres visualmente conectados entre sí podían formar comunidades aliadas que gracias a la ayuda mutua aumentaban sus oportunidades de sobrevivir en caso de un ataque o incluso pérdida de cosecha. Tales alianzas (Spielmann 1994: 51-52), confirmadas también por las fuentes españolas escritas de los siglos XVII-XIX, probablemente tuvieron un papel crucial para la existencia y la supervivencia en unas condiciones de vida en constante deterioro en la región Mesa Verde en el siglo XIII (tanto en términos del entorno natural, como la desintegración y el aumento de las presiones sociales, que incluso daban lugar a luchas intragrupales). Esto pudo tener vital importancia sobre todo para las comunidades y los asentamientos dispersos en un área bastante grande, por ejemplo en los cañones estudiados en el marco del proyecto polaco.

El surgimiento de la arquitectura defensiva y la intensificación de conflictos se produjeron probablemente a raíz de los cambios ambientales y climáticos adversos que en la segunda mitad del siglo XIII afectaron no solo la zona fronteriza entre Utah y Colorado, sino que tuvieron una extensión mucho más amplia, llegando a todas las áreas del suroeste, toda Norteamérica, e incluso todo el hemisferio norte; fue el comienzo de la Pequeña Edad de Hielo - período de enfriamiento que impactó varios lugares de América, Asia y Europa (incluida Polonia). En la región Mesa Verde el cambio climático se manifestó principalmente con el enfriamiento del clima y, sobre todo, con una disminución de precipitaciones y de los niveles de agua subterránea, a los que sumó la degradación del medio ambiente causada por su explotación excesiva por parte de los indios Pueblo. Los cambios ambientales y climáticos, combinados con la presión social y la creciente intensidad de conflictos y peleas, probablemente tanto con diverosos Pueblos nómadas imigrantes, como dentro de la cultura Pueblo, finalmente causaron un éxodo total de la región Mesa Verde.

A pesar de relativamente gran densidad de población del área a finales de los 70 y principios de los 80 del siglo XIII, el conjunto de asentamientos alrede- 
dor de Castle Rock Pueblo quedó completamente despoblado, al igual que toda la región Mesa Verde. Los indios Pueblo que sobrevivieron el período de sequía y peleas se marcharon hacia el sur y sureste, hoy en día norte y centro de Arizona y Nuevo México, donde se encontraron con otros grupos de indios Pueblo que habían vivido en esas regiones durante cientos de años. Los Pueblo contemporáneos todavía residen en Arizona (hopi) y una decena de Pueblos en Nuevo México (incluidos los zuñi, los acoma, los jemez). Los Pueblo nunca regresaron al área de Mesa Verde, a la que luego llegaron los navajo y los ute. Estos últimos, los ute de la montaña y los ute sureños, hoy tienen dos reservas en la parte sur de Colorado.

\section{Agradecimientos:}

El autor del presente artículo agradece cordialmente a las instituciones cuya ayuda permitió llevar a cabo los estudios en el marco del proyecto en los años 2011-2016, así como varias estancias anteriores a corto plazo. La investigación fue posible gracias al apoyo de los siguientes decanos de la Facultad de Historia de la Universidad Jaguelónica, la dirección del Instituto de Arqueología de la Universidad Jaguelónica, así como de socios estadounidenses, ante todo: el Centro del Patrimonio Anasazi, Bureau of Land Management (BLM) en Dolores, Colorado y el centro arqueológico Crow Canyon Archaeological Center (CCAC) en Cortez, Colorado, entre otros. Un agradecimiento individual por el patrocinio y el apoyo fi nanciero corresponde al Consulado General de los Estados Unidos en Cracovia. Además, en el año 2011, dos empresas apoyaron las actividades del proyecto: Krajowa Spółka Cukrowa S.A. y la compañía internacional Air Liquide con sede en Cracovia. En las etapas iniciales el proyecto de investigación recibió apoyo también de parte de la Sociedad Etnográfica Polaco-Americana de B. Malinowski (PAES / PATE) de Atlantic City, EE. UU. Desde 2014 la investigación ha sido financiada por el Centro Nacional de las Ciencias (Narodowe Centrum Nauki, números de subvención: UMO-2013/11/D/HS3/01879 y UMO-2017/26/E/HS3/01174). Por último, quisiera agradecer a la Sra. Alicja Zapolnik-Plachetka por la traducción de este texto al español.

\section{Bibliografía:}

Adler Michael A., Maripat Metcalf

1992 Archaeological Survey of Lower East Rock and Sand Canyons, Montezuma County, Colorado, Crow Canyon Archaeological Center.

Bandelier Adolf,

1916 Delight Makers, Dodd, Mead and Company, Nueva York.

Bryan Susan Montoya

2009 Study looks at early Navajo use of smoke signals, Entrada: 8 de junio, 
2009, sitio: http://www.indiancountrytoday.com/national/45844982. html, Associated Press Write.

Cameron Catherine M.

1995 Tracing Migration Pathways from the Receiving End, "Journal of Anthropological Archaeology”, № 14, pp. 203-211.

Cameron Catherine M.

2006 Leaving Mesa Verde, [en:] The Mesa Verde World: Explorations in Ancestral Pueblo Archaeology, red. D. G. Noble, pp. 139-147, School Charles Mona of American Research Press, Santa Fe.

2006

The Earliest Mesa Verdeans: Hunters, Foragers, and First Farmers, [en:] The Mesa Verde World: Explorations in Ancestral Pueblo Archaeology, red. D. G. Noble, pp. 9-17, School of American Research Press, Santa Fe.

Cole Sally J.

2009 Legacy on Stone. Rock Art of the Colorado Plateau and Four Corners Region, Johnson Books, Boulder.

Cordell Linda

1997 Archaeology of the Southwest, Academic Press, San Diego, Londres, Boston, Nueva York, Sydney, Tokyo, Toronto.

Dean Jeffrey, Carla Van West

2002 Environment-Behavior Relationships in Southwestern Colorado, [en:] Seeking the Center Place: Archaeology and Ancient Communities in Mesa Verde Region, red. M. D. Varien, R. H. Wilshusen, pp. 81-99, The University of Utah Press, Salt Lake City.

Ferguson T. J.

2002 Dowa Yalanne: The Architecture of Zuni Resistance and Social Change during the Pueblo Revolt, [en:] Archaeologies of the Pueblo Revolt: Identity, Meaning, and Renewal in the Pueblo World, red. R. W. Preucel, pp. 33-44, The University of New Mexico Press, Albuquerque.

Ferguson T. J., Chip Colwell-Chanthaphonh

2006 History is in the Land: Multivocal Tribal Traditions in Arizona's San Pedro Valley, The University of Arizona Press, Tucson.

Gleichman C. L., P. J. Gleichman

1992 The Lower Sand Canyon Survey, [en:] The Sand Canyon Archaeological Project: A Progress Report, red. W. D. Lipe, pp. 25-31, Occasional Papers, No. 2, Crow Canyon Archaeological Center, Cortez.

Haas Jonathan, Winifred Creamer

1996 The Role of Warfare in the Pueblo III Period, [en:] The Prehistoric Pueblo World A.D. 1150-1350, red. M. A. Adler, pp. 205-213, The University of Arizona Press, Tucson. 
Haas Jonathan, Winifred Creamer

1997 Warfare Among the Pueblos: Myth, History and Ethnography, "Ethnohistory”, № 2 (44), pp. 235-262.

Johnson David C.

2003 Mesa Verde Region Towers: A View from Above, “Kiva”, № 4 (68), pp. 323-340.

Kenzle Susan C.

1997 Enclosing walls in the Northern San Juan: Sociophysical Boundaries and Defensive Fortifications in the American Southwest, "Journal of Field Archaeology”, № 2 (24), pp. 195-210.

Kohler Timothy A.

2000 The Final 400 Years of Prehispanic Agricultural Society in the Mesa Verde Region, "Kiva", № 1 (66), pp. 195-202.

Kohler Timothy A., George J. Gumerman, Richard G. Reynoldys

2005 Simulating Ancient Societies, "Scientific American”, № 1 (293), pp. 76-84.

Kohler Timothy A., Mark D. Varien, Aaron M. Wright, Kristin A. Kuckelman (red.) 2008 Mesa Verde Migrations: New Archaeological Research and Computer Simulation Suggest why Ancestral Puebloans Deserted the Northern Southwest United States, “American Scientist”, № 96, pp. 146-153.

Kohler Timothy A., Mark D. Varien, Aaron M. Wright (red.)

2010 Leaving Mesa Verde. Peril and Change in the Thirteenth-Century Southwest, The University of Arizona Press, Tucson.

Kuckelman Kristin A.

2002 Thirteenth-Century Warfare in the Central Mesa Verde Region, [en:] Seeking the Center Place: Archaeology and Ancient Communities in Mesa Verde Region, red. M. D. Varien, R. H. Wilshusen, pp. 233-253, The University of Utah Press, Salt Lake City.

Kuckelman Kristin A. (red.)

The Archaeology of Castle Rock Pueblo: A Thirteenth-Century Village in Southwestern Colorado, 2000, entrada 5 de abril 2014, sitio: http:// www.crowcanyon.org/ResearchReports/CastleRock/Text/crpw_contentsvoume.asp

LeBlanc Steven A.

1999 Prehistoric Warfare in the American Southwest, University of Utah Press, Salt Lake City 1999.

Lightfoot Ricky R., Kristin A. Kuckelman

2001 A Case of Warfare in the Mesa Verde Region, [en:] Deadly Landscapes: Case Studies in Prehistoric Southwestern Warfare, red. G. E. Rice, S. A. LeBlanc, pp. 51-64, University of Utah Press, Salt Lake City 2001. 
Lipe William D.

1995 The Depopulation of the Northern San Juan: Conditions in the Turbulent 1200s., "Journal of Anthropological Archaeology”, № 14, pp. 143169, 1995.

Lipe William D.

2002 Social Power in the Central Mesa Verde Region, A.D. 1150-1290, [en:] Seeking the Center Place: Archaeology and Ancient Communities in Mesa Verde Region, red. M. D. Varien, R. H. Wilshusen, pp. 203-232, The University of Utah Press, Salt Lake City 2002.

Lipe William D., Mark D. Varien

1999 Pueblo III (A.D. 1150-1300). Chapter 9, [en:] Colorado Prehistory: A Context for the Southern Colorado River Basin, red. W. D. Lipe, M. D. Varien, R. H. Wilshusen, pp. 290-352, Colorado Council of Professional Archaeologists, Denver 1999.

Matson Richard G.

1991 The Origins of Southwestern Agriculture, The University of Arizona Press Tucson 1991.

Ortman Scott G.

2008 Action, Place, and Space in the Castle Rock Community, [en:] The Social Construction of Communities: Agency, Structure, and Identity in the Prehispanic Southwest, red. M. D. Varien, J. M. Porter, pp. 125-154, Altamira Press, Lanham, Boulder, Nueva York, Toronto, Plymouth 2008.

Palonka Radosław

2011 Defensive Architecture and the Depopulation of the Mesa Verde Region, Utah-Colorado, USA in the XIII Century A.D, Jagiellonian University Press, Kraków 2011.

Palonka Radosław

2013 Pueblo culture settlement structure in the central Mesa Verde Region, Utah-Colorado in the Thirteenth Century AD., [en:] Environment and subsistence - forty years after Janusz Kruk's ,,Settlement studies...” (= StudienzurArchäologie in Ostmitteleuropa/Studia nad Pradziejami Europy Środkowej 11), red. S. Kadrow, P. Włodarczak, pp. 193-224, Mitel \& Verlag Dr. Rudolf Habelt GmbH, Rzeszów, Bonn.

Palonka Radosław

2014 Research on the Pueblo culture settlement system from the North American Southwest: Results of Sand Canyon-Castle Rock Community Archaeological Project, "Studia Humanistyczne AGH”, № 2 (13), pp. 62-83.

Palonka Radosław

2019 Towers as an Architectural Element of Pueblo Culture in the Mesa Verde Region, Utah-Colorado, in the 12th-13th Century A.D. Papers 
from 3rd Conference on Towers in Medieval Europe "URBS TURRITA - Towers in Medieval Cities and Towns".

Palonka Radosław, Anna Słupianek, Jakub Nawrot

2015 Pueblo Community in the Lower Sand Canyon Locality, Colorado: Preliminary report of The Sand Canyon-Castle Rock Community Archaeological Project, 2011-2014, "Contributions in New World Archaeology", red. J.K. Kozłowski, R. Palonka, M. Wasilewski, J. Źrałka, № 9, pp. 69-92.

Plog, Stephen

1997 Ancient Peoples of the American Southwest, Thames \& Hudson, Londres.

Schaafsma Polly

1980 Indian Rock Art of the Southwest. University of New Mexico Press, Albuquerque.

Schaafsma Polly

2003 Warrior, Shield, and Star: Imagery and Ideology of Pueblo Warfare. Western Edge Press.

Schulman A.

1950 Pre-Columbian Towers in the Southwest, “American Antiquity” № 4 (15), pp. 288-297.

Spielmann K. A.

1994 Clustered Confederacies: Sociopolitical Organization in the Protohistoric Rio Grande, [en:] Ancient Southwest Community: Models and Methods for the Study of Prehistoric Social Organization, red. H. Wills and R. Leonard, pp. 45-54. University of New Mexico Press Albuquerque.

Thompson Ian M.

2002 Native American Perspectives on Sand Canyon Pueblo and Other Ancestral Sites, [en:] Seeking the Center Place: Archaeology and Ancient Communities in Mesa Verde Region, red. M. D. Varien, R. H. WilshuThompson Ian M. sen, pp. 257-262, The University of Utah Press, Salt Lake City.

2004 The Towers of Hovenweep, Canyonlands Natural History Association, Moab.

Towner Ronald H.

1999 Eighteenth-Century Navajo Defensive Sites in the Dinetah, "Archaeology Southwest”, № 2 (13), pp. 8-9.

Towner Ronald H.

2004 Defending the Dinétah. Pueblitos in the Ancestral Navajo Heartland. The University of Utah Press, Salt Lake City.

Van Dyke Ruth M., R. Kyle Bocinsky, Thomas C. Windes, Tucker J. Robinson 
2016 Great houses, shrines, and high places: Intervisibility in the Chacoan world, "American Antiquity”, № 2 (81), pp. 205-230.

Van West Carla R., Jeffrey S. Dean

2000 Environmental Characteristics of the A.D. 900-1300 Period in the Central Mesa Verde Region, "Kiva”, № 1 (66), pp. 19-44.

Varien Mark D.

1999 Sedentism and Mobility in a Social Landscape. Mesa Verde \& Beyond. The University of Arizon Press, Tucson.

Varien Mark D.

2000 Introduction, “Kiva”, № 1 (66), pp. 5-18.

Varien Mark D., Scott G. Ortman, Timothy A. Kohler, Donna M. Glowacki, C. David Johnson,

2007 Historical Ecology in the Mesa Verde Region: Results from the Village Ecodynamics Project, “American Antiquity”, № 2 (72), pp. 273-299.

Wilshusen Richard H.

1999 Basketmaker III (A.D. 500-750). Chapter 6, [en:] Colorado Prehistory: a Context for the Southern Colorado River Basin, red. W. D. Lipe, M. D. Varien, R. H. Wilshusen, pp. 166-195, Colorado Council of Professional Archaeologists, Denver.

Wilshusen Richard $\mathrm{H}$.

2002 Estimating Population in the Central Mesa Verde Region, [en:] Seeking the Center Place: Archaeology and Ancient Communities in Mesa Verde Region, red. M. D. Varien, R. H. Wilshusen, pp. 101-120, The University of Utah Press, Salt Lake City. 
